\title{
Gravitacijski separatori plin/kapljevina. Dio IV.
}

\section{E. Beer ${ }^{*}$}

Aleja Blaža Jurišića 9, 10000 Zagreb

\section{\| Sažetak}

Nastavak postupaka proračuna gravitacijskih separatora. Dani su postupci proračuna za vodoravne trofazne gravitacijske separatore.

\| Ključne riječi

Gravitacijski separatori, separatori plin/kapljevina/kapljevina, dimenzioniranje

\section{Primjer 5. Trofazni vodoravni separator - konvencionalni}

To je prvi od četiri tipa trofaznih vodoravnih separatora (slika 24a).

Proračun se temelji na brzini plina u parnom prostoru separatora koja osigurava izdvajanje kapljica kapljevine iz plina i na dovoljnom vremenu zadržavanja kapljevine u separatoru za postizanje željenog odvajanja dviju kapljevina (minimalni promjer kapljice dispergirane faze koja se izdvaja iz kontinuirane faze). Brzina plina računa se ovisno o tome ugrađuje li se odvajač kapljica ili ne. Unutarnji promjer separatora zadan je brzinom i volumnim protokom plina.

Kao i u prethodnim primjerima ne računa se s volumenima podnica. Taj je volumen neka vrsta sigurnosne margine.

\section{Podatci za proračun}

Treba načiniti proračun trofaznog separatora za odvajanje plinsko/kapljevite smjese sljedećih karakteristika:

protok plina, $Q_{\mathrm{vG}}=3350 \mathrm{~m}^{3} \mathrm{~h}^{-1}$

gustoća plina, $\rho_{\mathrm{G}}=8,5 \mathrm{~kg} \mathrm{~m}^{-3}$

viskoznost plina, $\mu_{\mathrm{G}}=0,01 \mathrm{mPa} \mathrm{s}$

protok lakše kapljevine, $Q_{\mathrm{vLI}}=28,0 \mathrm{~m}^{3} \mathrm{~h}^{-1}$

gustoća kapljevine, $\rho_{\mathrm{LI}}=650 \mathrm{~kg} \mathrm{~m}^{-3}$

viskoznost lakše kapljevine, $\mu_{\mathrm{LI}}=0,24 \mathrm{mPa} \mathrm{s}$

protok teže kapljevine, $Q_{\mathrm{vLh}}=15,0 \mathrm{~m}^{3} \mathrm{~h}^{-1}$

gustoća teže kapljevine, $\rho_{\mathrm{Lh}}=995 \mathrm{~kg} \mathrm{~m}^{-3}$

viskoznost teže kapljevine, $\mu_{\mathrm{Lh}}=0,682 \mathrm{mPa} \mathrm{s}$

granični promjer kapljice koja se odvaja iz kapljevi-

ne (lakši i teže), $D_{\mathrm{p}}=150 \mathrm{~mm}$

radni tlak separatora, $p=10$ bar

u separator se ugrađuje odvajač kapljica distributor ulazne smjese je deflektor

vrijeme zadržavanja, $t_{\mathrm{h}}=5 \mathrm{~min}$

vrijeme poremećaja, $t_{\mathrm{s}}=3 \mathrm{~min}$

sigurnosna margina/sigurnosni faktor, $F_{\mathrm{s}}=1,15$

\section{Souders-Brownov K-faktor i granična brzina plina}

$U$ separator će biti ugrađen odvajač kapljica od čelične mrežice, pa Souders-Brownov $K$-faktor računamo korelacijama za odvajače iz mrežice (Koch-Otto York) za apsolutni radni tlak $p=11,013$ bar:

$$
\begin{aligned}
K & =[0,1123-0,007 \ln (p / \text { bar })] \mathrm{ms}^{-1} \\
& =[0,1123-0,007 \ln (11,013)] \mathrm{ms}^{-1}=0,0955 \mathrm{~ms}^{-1}
\end{aligned}
$$

Granična brzina plina iz jedn. 15 (računamo s lakšom kapljevinom):

$$
\begin{aligned}
u_{\mathrm{t}}=u_{\mathrm{d}} & =K \sqrt{\frac{\rho_{\mathrm{L}}-\rho_{\mathrm{G}}}{\rho_{\mathrm{G}}}}=0,0955 \sqrt{\frac{650-8,5}{8,5}} \mathrm{~ms}^{-1} \\
& =0,830 \mathrm{~ms}^{-1}
\end{aligned}
$$

\section{Brzine odvajanja kapljevina iz Stokesove korelacije}

$$
\begin{aligned}
u_{\mathrm{Lh}} & =\frac{g}{18} D_{\mathrm{p}}^{2} \frac{\rho_{\mathrm{Lh}}-\rho_{\mathrm{LI}}}{\mu_{\mathrm{LI}}}=\frac{9,806}{18} \cdot\left(150 \cdot 10^{-6}\right)^{2} \frac{995-650}{0,00024} \mathrm{~m} \mathrm{~s}^{-1} \\
& =0,0176 \mathrm{~m} \mathrm{~s}^{-1} \\
u_{\mathrm{LI}} & =\frac{g}{18} D_{\mathrm{p}}^{2} \frac{\rho_{\mathrm{Lh}}-\rho_{\mathrm{LI}}}{\mu_{\mathrm{Lh}}}=\frac{9,806}{18} \cdot\left(150 \cdot 10^{-6}\right)^{2} \frac{995-865}{0,000682} \mathrm{~m} \mathrm{~s}^{-1} \\
& =0,00620 \mathrm{~m} \mathrm{~s}^{-1}
\end{aligned}
$$

Obje brzine su veće od maksimalne brzine izdvajanja $u_{\max }=0,00425 \mathrm{~m} \mathrm{~s}^{-1}$ pa uzimamo:

$$
\begin{aligned}
& u_{\mathrm{Lh}}=0,00425 \mathrm{~m} \mathrm{~s}^{-1} \\
& u_{\mathrm{LI}}=0,00425 \mathrm{~m} \mathrm{~s}^{-1}
\end{aligned}
$$




\section{Volumeni zadržavanja i poremećaja}

Zadržaj:

$$
\begin{aligned}
V_{\mathrm{h}} & =t_{\mathrm{h}}\left(Q_{\mathrm{vLI}}+Q_{\mathrm{vLh}}\right) \\
& =5 \cdot 60 \mathrm{~s} \cdot(0,00894+0,00479) \mathrm{m}^{3} \mathrm{~s}^{-1} \\
& =4,121 \mathrm{~m}^{3}
\end{aligned}
$$

Poremećaj:

$$
\begin{aligned}
V_{\mathrm{s}} & =t_{\mathrm{s}}\left(Q_{\mathrm{vLL}}+Q_{\mathrm{vLh}}\right) \\
& =3 \cdot 60 \mathrm{~s} \cdot(0,00894+0,00479) \mathrm{m}^{3} \mathrm{~s}^{-1} \\
& =2,473 \mathrm{~m}^{3}
\end{aligned}
$$

\section{Promjer separatora}

Uzimamo da je omjer površine presjeka parnog prostora i presjeka separatora 0,7 .

Uz radni tlak od 10 bar preporučeni omjer $L / D$ je između 1,5 i 3 . Uzimamo $L / D=2,0$.

Promjer separatora:

$$
\begin{gathered}
D_{\mathrm{i}}=\left[\frac{4\left(V_{\mathrm{h}}+V_{\mathrm{s}}\right)}{0,6 \pi \cdot L / D}\right]^{1 / 3}=\left[\frac{4(4,121+2,473) \mathrm{m}^{3}}{0,6 \pi \cdot 2,0}\right]^{1 / 3}=1,913 \mathrm{~m} \\
L=D_{\mathrm{i}} \cdot L / D=1,913 \cdot 2,0 \mathrm{~m}=3,825 \mathrm{~m} \\
A_{\mathrm{t}}=\frac{\pi D_{\mathrm{i}}^{2}}{4}=\frac{\pi \cdot(1,913 \mathrm{~m})^{2}}{4}=2,873 \mathrm{~m}^{2}
\end{gathered}
$$

5. Visina sloja teže kapljevine, $H_{\llcorner\mathrm{h}}$, lakše kapljevine, $H_{\mathrm{L}}$ volumena poremećaja, $H_{\mathrm{s}}$ i parnog prostora, $H_{v}$

Teža kapljevina:

$$
\begin{gathered}
V_{\mathrm{Lh}}=Q_{\mathrm{vLh}} \cdot t_{\mathrm{h}}=0,00479 \mathrm{~m}^{3} \mathrm{~s}^{-1} \cdot 5 \cdot 60 \mathrm{~s}=1,4375 \mathrm{~m}^{3} \\
A_{\mathrm{Lh}}=\frac{V_{\mathrm{Lh}}}{L}=\frac{1,437 \mathrm{~m}^{3}}{3,825 \mathrm{~m}}=0,376 \mathrm{~m}^{2}
\end{gathered}
$$

Lakša kapljevina:

$$
\begin{aligned}
V_{\mathrm{LI}}=Q_{\mathrm{vL}} \cdot t_{\mathrm{h}} & =0,00894 \mathrm{~m}^{3} \mathrm{~s}^{-1} \cdot 5 \cdot 60 \mathrm{~s}=2,683 \mathrm{~m}^{3} \\
A_{\mathrm{LI}} & =\frac{V_{\mathrm{LI}}}{L}=\frac{2,683 \mathrm{~m}^{3}}{3,825 \mathrm{~m}}=0,701 \mathrm{~m}^{2}
\end{aligned}
$$

Poremećaj:

$$
A_{\mathrm{s}}=\frac{V_{\mathrm{s}}}{L}=\frac{2,4725 \mathrm{~m}^{3}}{3,825 \mathrm{~m}}=0,646 \mathrm{~m}^{2}
$$

Iz korelacija za odnos visine i površine kružnog odsječka:

$$
\frac{A_{\mathrm{Lh}}}{A_{\mathrm{t}}}=\frac{0,376 \mathrm{~m}^{2}}{2,873 \mathrm{~m}^{2}}=0,131
$$

$$
H_{\mathrm{Lh}}=0,361 \mathrm{~m}
$$

$$
\begin{gathered}
\frac{A_{\mathrm{Lh}}+A_{\mathrm{LI}}}{A_{\mathrm{t}}}=\frac{0,376 \mathrm{~m}^{2}+0,646 \mathrm{~m}^{2}}{2,873 \mathrm{~m}^{2}}=0,356 \\
H_{\mathrm{Lh}}+H_{\mathrm{LI}}=0,768 \mathrm{~m} ; H_{\mathrm{LI}}=0,407 \mathrm{~m}
\end{gathered}
$$

$$
\begin{aligned}
\frac{A_{\mathrm{Lh}}+A_{\mathrm{Ll}}+A_{\mathrm{s}}}{A_{\mathrm{t}}} & =\frac{0,376 \mathrm{~m}^{2}+0,701 \mathrm{~m}^{2}+0,646 \mathrm{~m}^{2}}{2,873 \mathrm{~m}^{2}}=0,600 \\
H_{\mathrm{Lh}} & +H_{\mathrm{LI}}+H_{\mathrm{s}}=1,105 \mathrm{~m} ; H_{\mathrm{s}}=0,337 \mathrm{~m} \\
H_{\mathrm{v}} & =D_{\mathrm{i}}-H_{\mathrm{Lh}}-H_{\mathrm{L}}-H_{\mathrm{s}} \\
& =1,887 \mathrm{~m}-0,361 \mathrm{~m}-0,407 \mathrm{~m}-0,337 \mathrm{~m} \\
& =0,782 \mathrm{~m}
\end{aligned}
$$

$A_{v}=(1-0,521) \cdot A_{\mathrm{t}}=(1-0,521) \cdot 2,873 \mathrm{~m}^{2}=1,376 \mathrm{~m}^{2}$

\section{Vremena zadržavanja i odvajanja i} minimalne duljine separatora

Plin:

$$
\begin{gathered}
t_{\text {sep }}=\frac{H_{v}}{u_{d}}=\frac{0,806 \mathrm{~m}}{0,830 \mathrm{~m} \mathrm{~s}^{-1}}=0,971 \mathrm{~s} \\
u_{\mathrm{G}}=\frac{Q_{v \mathrm{~V}}}{A_{v}}=\frac{1,070 \mathrm{~m}^{3} \mathrm{~s}^{-1}}{1,149 \mathrm{~m}^{2}}=0,931 \mathrm{~m} \mathrm{~s}^{-1} \\
L_{\text {min }, \mathrm{G}}=t_{\text {sep }} \cdot u_{\mathrm{G}}=0,97 \mathrm{~s} \cdot 0,931 \mathrm{~m} \mathrm{~s}^{-1}=0,904 \mathrm{~m}
\end{gathered}
$$

Lakša kapljevina:

$$
\begin{gathered}
t_{\text {sep }, \mathrm{LI}}=\frac{H_{\mathrm{LI}}}{u_{\mathrm{LI}}}=\frac{0,361 \mathrm{~m}}{0,00425 \mathrm{~m} \mathrm{~s}^{-1}}=84,9 \mathrm{~s} \\
u_{\mathrm{LI}}=\frac{Q_{\mathrm{vLI}}}{A_{\mathrm{LI}}}=\frac{0,00479 \mathrm{~m}^{3} \mathrm{~s}^{-1}}{0,376 \mathrm{~m}^{2}}=0,01275 \mathrm{~m} \mathrm{~s}^{-1} \\
L_{\text {min }, \mathrm{LI}}=t_{\text {sep }, \mathrm{Ll}} \cdot u_{\mathrm{LI}}=84,9 \mathrm{~s} \cdot 0,01275 \mathrm{~m} \mathrm{~s}^{-1}=1,082 \mathrm{~m}
\end{gathered}
$$

Teža kapljevina

$$
\begin{gathered}
t_{\text {sep }, \mathrm{Lh}}=\frac{H_{\mathrm{Lh}}}{u_{\mathrm{Lh}}}=\frac{0,407 \mathrm{~m}}{0,00425 \mathrm{~m} \mathrm{~s}^{-1}}=95,7 \mathrm{~s} \\
u_{\mathrm{Lh}}=\frac{Q_{\mathrm{vLh}}}{A_{\mathrm{Lh}}}=\frac{0,00894 \mathrm{~m}^{3} \mathrm{~s}^{-1}}{0,701 \mathrm{~m}^{2}}=0,01275 \mathrm{~m} \mathrm{~s}^{-1} \\
L_{\min , \mathrm{Lh}}=t_{\mathrm{sep}, \mathrm{Lh}} \cdot u_{\mathrm{Lh}}=95,7 \mathrm{~s} \cdot 0,01275 \mathrm{~m} \mathrm{~s}^{-1}=1,220 \mathrm{~m}
\end{gathered}
$$

Minimalne duljine separatora potrebne za odvajanje:

Kapljica iz plina $\quad L_{\min }=0,904 \mathrm{~m}$

Lakše iz teže kapljevine $L_{\min }=1,220 \mathrm{~m}$

Teže iz lakše kapljevine $L_{\min }=1,082 \mathrm{~m}$ 
Kako vidimo, duljina separatora nadmašuje potrebne duljine separacije i očito je da je kontrolirajući faktor za dimenzioniranje traženo vrijeme zadržavanja kapljevine u separatoru i zadano vrijeme poremećaja. Tu bi se mogao eventualno smanjiti promjer separatora jer je visina parnog prostora veća od potrebne minimalne visine za ugradnju odvajača kapljica. Kako će to istodobno smanjiti i visinu parnog prostora, treba voditi računa o tome jer u separator treba ugraditi odvajač kapljica.

Pokušaj s većim udjelom površine presjeka zauzetom kapljevitom fazom daje:

$$
\begin{aligned}
D_{\mathrm{i}} & =\left[\frac{4\left(V_{\mathrm{h}}+V_{\mathrm{s}}\right)}{0,7 \pi \cdot L / D}\right]^{1 / 3} \\
& =\left[\frac{4\left(4,121 \mathrm{~m}^{3}+2,473 \mathrm{~m}^{3}\right)}{0,7 \pi \cdot 2,0}\right]^{1 / 3}=1,817 \mathrm{~m}
\end{aligned}
$$

Ostali rezultati su:

\begin{tabular}{l|c}
\hline promjer & $1,817 \mathrm{~m}$ \\
duljina & $3,825 \mathrm{~m}$ \\
visina parnog prostora & $0,618 \mathrm{~m}$ \\
visina sloja teže kapljevine & $0,381 \mathrm{~m}$ \\
visina sloja lakše kapljevine & $0,438 \mathrm{~m}$ \\
visina sloja poremećaja & $0,380 \mathrm{~m}$ \\
\hline minimalno potrebna duljina: & \\
\hline - za izdvajanje kapljica iz plina & $1,025 \mathrm{~m}$ \\
- za izdvajanje teže kapljevine iz lakše & $1,248 \mathrm{~m}$ \\
- za izdvajanje lakše kapljevine iz teže & $1,087 \mathrm{~m}$ \\
\hline
\end{tabular}

Dobiven je manji promjer i nešto su povećane potrebne duljine izdvajanja. Daljnje smanjenje promjera ili eventualno smanjenje duljine separatora vjerojatno bi smanjilo visinu parnog prostora ispod 0,6 m, što nije prihvatljivo s obzirom na postavljanje odvajača kapljica.

\section{Priključci}

Proračun priključaka dao je sljedeće.

\begin{tabular}{l|c}
\hline Namjena & Nazivni promjer \\
\hline ulaz pojne smjese & $16^{\prime \prime}$ Sch 20 \\
izlaz plina & $16^{\prime \prime}$ Sch 20 \\
izlaz lakše kapljevine & 4 "Sch 20 \\
izlaz teže kapljevine & 3" Sch 20 \\
\hline
\end{tabular}

Za detalje postupka i proračun vidi primjer 1.

\section{Pad tlaka}

\begin{tabular}{l|c}
\hline ulaz smjese & $748 \mathrm{~Pa}$ \\
izlaz plina & $150 \mathrm{~Pa}$ \\
\hline žičana mrežica, $1 \mathrm{~m}^{2}$ & $292 \mathrm{~Pa}$ \\
\hline pločasti - jednostruki džepovi, $1 \mathrm{~m}^{2}$ & $38 \mathrm{~mm}$ stupca kapljevine \\
- dvostruki džepovi, $1 \mathrm{~m}^{2}$ & $146 \mathrm{~Pa}$ \\
\hline
\end{tabular}

Za detalje postupka i proračun vidi primjer 1 .

\section{Rekapitulacija dimenzija}

\begin{tabular}{c|r}
\hline promjer & $1820 \mathrm{~mm}$ \\
duljina & $3635 \mathrm{~mm}$ \\
$H / D$ & 1,997 \\
$H_{\mathrm{I}}$ & $430 \mathrm{~mm}$ \\
$H_{\mathrm{h}}$ & $380 \mathrm{~mm}$ \\
$H_{\mathrm{s}}$ & $380 \mathrm{~mm}$ \\
$\mathrm{HLL}$ & $1190 \mathrm{~mm}$ \\
$\mathrm{NLL}$ & $810 \mathrm{~mm}$ \\
IL & $380 \mathrm{~mm}$ \\
\hline \multicolumn{1}{c|}{ priključci } \\
\hline ulaz smjese & $16^{\prime \prime}$ \\
izlaz plina & $16^{\prime \prime}$ \\
izlaz lakše kapljevine & $4^{\prime \prime}$ \\
izlaz teže kapljevine & $3^{\prime \prime}$ \\
\hline
\end{tabular}

\section{Primjer 6. Trofazni vodoravni separator sa slivnikom za težu kapljevinu}

Taj tip separatora je konvencionalni separator prilagođen odvajanju trofazne smjese s malom količinom teže kapljevine. Kako bi radi male količine teže kapljevine visina međufaznog nivoa a posebice visina minimalnog nivoa bile jako male i održavanje međufaznog nivoa praktično nemoguće, teža se kapljevina sakuplja u slivniku u kojem se regulira i međufazni nivo.

Proračun se temelji na brzini plina u parnom prostoru separatora koja osigurava izdvajanje kapljica kapljevine iz plina i na dovoljnom vremenu zadržavanja lakše kapljevine u separatoru za postizanje željenog odvajanja teže iz lakše kapljevine. Slivnik se posebno dimenzionira kao okomiti separator.

\section{Podatci za proračun}

Treba načiniti proračun trofaznog separatora za odvajanje plinsko/kapljevinte smjese sljedećih karakteristika:

protok plina, $Q_{v G}=3000 \mathrm{~m}^{3} \mathrm{~h}^{-1}$

gustoća plina, $\rho_{\mathrm{G}}=3,5 \mathrm{~kg} \mathrm{~m}^{-3}$ 
viskoznost plina, $\mu_{\mathrm{G}}=0,01 \mathrm{mPa} \mathrm{s}$

protok lakše kapljevine, $Q_{\mathrm{mL}}=20,0 \mathrm{t} \mathrm{h}^{-1}$

gustoća lakše kapljevine, $\rho_{\mathrm{LI}}=875 \mathrm{~kg} \mathrm{~m}^{-3}$

viskoznost lakše kapljevine, $\mu_{\mathrm{LI}}=0,24 \mathrm{mPa} \mathrm{s}$

protok teže kapljevine, $Q_{\mathrm{mLh}}=2,0 \mathrm{t} \mathrm{h}^{-1}$

gustoća teže kapljevine, $\rho_{\mathrm{Lh}}=995 \mathrm{~kg} \mathrm{~m}^{-3}$

viskoznost teže kapljevine, $\mu_{\mathrm{Lh}}=0,682 \mathrm{mPa} \mathrm{s}$

granični promjer kapljice koja se odvaja iz plina, $D_{\mathrm{p}}=100 \mathrm{~mm}$

radni tlak separatora, $p=2$ bar

u separator se ne ugrađuje odvajač kapljica

distributor ulazne smjese je deflegmator

vrijeme zadržavanja, $t_{\mathrm{h}}=5 \mathrm{~min}$

vrijeme poremećaja, $t_{\mathrm{s}}=2 \mathrm{~min}$

sigurnosna margina/sigurnosni faktor, $F_{\mathrm{s}}=1,15$

\section{Souders-Brownov K-faktor i granična brzina plina}

U separator neće biti ugrađen odvajač kapljica. Souders-Brownov $K$-faktor računamo korelacijom GPSA za radni tlak $p=2,0$ bar:

$$
\begin{aligned}
K & =\left(0,109728-4,4216 \cdot 10^{-4} \mathrm{p} / \mathrm{bar}\right) \mathrm{ms}^{-1} \\
& =\left(0,109728-4,4216 \cdot 10^{-4} \cdot 2\right) \mathrm{ms}^{-1} \\
& =0,1088 \mathrm{~ms}^{-1}
\end{aligned}
$$

Kako se ne ugrađuje odvajač kapljica, preporuka je izračunati $K$-faktor dijeliti s 2 .

$$
K=0,0544 \mathrm{~ms}^{-1}
$$

Granična brzina plina iz jedn. 15 (računamo s lakšomkapljevinom):

$u_{\mathrm{t}}=u_{\mathrm{d}}=K \sqrt{\frac{\rho_{\mathrm{L}}-\rho_{\mathrm{G}}}{\rho_{\mathrm{G}}}}=0,0544 \mathrm{~m} \mathrm{~s}^{-1} \sqrt{\frac{785-3,5}{3,5}}=0,813 \mathrm{~m} \mathrm{~s}^{-1}$

\section{Brzine odvajanja kapljevina iz Stokesove korelacije}

Brzina odvajanja kapljica teže kapljevine iz lakše kapljevine:

$$
\begin{aligned}
u_{\mathrm{Lh}} & =\frac{g}{18} D_{\mathrm{p}}^{2} \frac{\rho_{\mathrm{Lh}}-\rho_{\mathrm{LI}}}{\mu_{\mathrm{Ll}}}=\frac{9,806}{18} \cdot\left(100 \cdot 10^{-6}\right)^{2} \frac{995-785}{0,00024} \mathrm{~m} \mathrm{~s}^{-1} \\
& =0,00477 \mathrm{~m} \mathrm{~s}^{-1}
\end{aligned}
$$

Brzina je veća od $0,00425 \mathrm{~m} \mathrm{~s}^{-1}$ pa uzimamo $u_{\mathrm{Lh}}=0,00425 \mathrm{~ms}^{-1}$.

Brzina odvajanja kapljica lakše kapljevine iz teže kapljevine:

$$
\begin{aligned}
u_{\mathrm{LI}} & =\frac{g}{18} D_{\mathrm{p}}^{2} \frac{\rho_{\mathrm{Lh}}-\rho_{\mathrm{LL}}}{\mu_{\mathrm{Lh}}}=\frac{9,806}{18} \cdot\left(100 \cdot 10^{-6}\right)^{2} \frac{995-785}{0,000682} \mathrm{~m} \mathrm{~s}^{-1} \\
& =0,00168 \mathrm{~m} \mathrm{~s}^{-1}
\end{aligned}
$$

\section{Volumeni zadržavanja i poremećaja}

Lakša kapljevina - zadržaj:

$$
V_{\mathrm{LI}}=t_{\mathrm{h}} \cdot Q_{\mathrm{vLI}}=5 \cdot 60 \mathrm{~s} \cdot 0,00639 \mathrm{~m}^{3} \mathrm{~s}^{-1}=1,917 \mathrm{~m}^{3}
$$

Poremećaj:

$$
V_{\mathrm{sLI}}=t_{\mathrm{s}} \cdot Q_{\mathrm{vLI}}=2 \cdot 60 \mathrm{~s} \cdot 0,00639 \mathrm{~m}^{3} \mathrm{~s}^{-1}=0,77 \mathrm{~m}^{3}
$$

Teža kapljevina - zadržaj:

$$
V_{\mathrm{Lh}}=t_{\mathrm{h}} \cdot Q_{\mathrm{vLh}}=5 \cdot 60 \mathrm{~s} \cdot 0,000639 \mathrm{~m}^{3} \mathrm{~s}^{-1}=0,192 \mathrm{~m}^{3}
$$

Poremećaj:

$$
V_{\mathrm{sLh}}=t_{\mathrm{s}} \cdot Q_{\mathrm{vLh}}=2 \cdot 60 \mathrm{~s} \cdot 0,000639 \mathrm{~m}^{3} \mathrm{~s}^{-1}=0,077 \mathrm{~m}^{3}
$$

\section{Promjer separatora}

Uz radni tlak od 2 bar preporučeni omjer $L / D$ je između 1,5 i 3 . Uzimamo $L / D=2,0$.

Promjer separatora:

$$
\begin{gathered}
D_{\mathrm{i}}=\left[\frac{4\left(V_{\mathrm{LL}}+V_{\mathrm{SL}}\right)}{0,6 \pi \frac{L}{D}}\right]^{1 / 3}=\left[\frac{4(1,917+0,77) \mathrm{m}^{3}}{0,6 \pi \cdot 2,0}\right]^{1 / 3}=1,417 \mathrm{~m} \\
L=D_{\mathrm{i}} \cdot L / D=1,417 \mathrm{~m} \cdot 2,0=2,834 \mathrm{~m} \\
A_{\mathrm{t}}=\frac{\pi D_{\mathrm{i}}^{2}}{4}=\frac{\pi \cdot(1,417 \mathrm{~m})^{2}}{4}=1,587 \mathrm{~m}^{2}
\end{gathered}
$$

Ne ugrađuje se odvajač kapljica i uzimamo da je visina parnog postora $H_{v}=0,3 \mathrm{~m}$.

Uz omjer $H_{\sqrt{ }} / D_{\mathrm{i}}=0,212$ iz korelacije za površinu i visinu kružnog segmenta: $A_{v}=0,244 \mathrm{~m}^{2}$.

\section{Visine nivoa $L L L, N L L$ i $H L L$}

Površina presjeka koji zauzima lakša kapljevina do LLL:

uzimamo $L L L=0,250 \mathrm{~m}$

$x=0,25 / 1,417=0,176$; iz korelacija u tablici 31 :

$A_{\mathrm{LLL}}=0,0929 \mathrm{~m}^{2}$.

Površina presjeka koju zauzima lakša kapljevina do NLL:

$$
\begin{gathered}
\frac{1,917 \mathrm{~m}^{3}}{2,834 \mathrm{~m}}+0,188 \mathrm{~m}^{2}=0,864 \mathrm{~m}^{2} \\
x=0,864 / 1,587=0,544 ; \mathrm{NLL}=0,716 \mathrm{~m} . \\
\mathrm{HLL}=D_{\mathrm{i}}-H_{\mathrm{v}}=1,417 \mathrm{~m}-0,300 \mathrm{~m}=1,117 \mathrm{~m} .
\end{gathered}
$$




\begin{tabular}{c|c}
\hline promjer & $1,417 \mathrm{~m}$ \\
duljina & $2,834 \mathrm{~m}$ \\
HLL & $1,117 \mathrm{~m}$ \\
NLL & $0,716 \mathrm{~m}$ \\
LLL & $0,250 \mathrm{~m}$ \\
\hline
\end{tabular}

\section{Vremena zadržavanja, separacije $i$ potrebna duljina separatora}

Izdvajanje kapljevine iz plina:

$$
\begin{gathered}
u_{\mathrm{G}}=\frac{Q_{\mathrm{vG}}}{A_{\mathrm{v}}}=\frac{0,958 \mathrm{~m}^{3} \mathrm{~s}^{-1}}{0,244 \mathrm{~m}^{2}}=3,933 \mathrm{~m} \mathrm{~s}^{-1} \\
t_{\mathrm{hG}}=\frac{L}{u_{\mathrm{G}}}=\frac{2,834 \mathrm{~m}}{3,933 \mathrm{~m} \mathrm{~s}^{-1}}=0,721 \mathrm{~s} \\
t_{\text {sep }}=\frac{H_{\mathrm{v}}}{u_{\mathrm{d}}}=\frac{0,300 \mathrm{~m}}{0,813 \mathrm{~m} \mathrm{~s}^{-1}}=0,369 \mathrm{~s}
\end{gathered}
$$

Izdvajanja teže kapljevine iz lakše

Vrijeme zadržavanja lakše kapljevine:

$$
\begin{aligned}
t_{\mathrm{hLI}} & =\frac{\left(A_{\mathrm{NLL}}+A_{\mathrm{LLL}}\right) \cdot L}{Q_{\mathrm{VLI}}} \\
& =\frac{\left(0,676 \mathrm{~m}^{2}+0,188 \mathrm{~m}^{2}\right) \cdot 2,834 \mathrm{~m}}{0,00639 \mathrm{~m}^{3} \mathrm{~s}^{-1}} \\
& =383,2 \mathrm{~s}
\end{aligned}
$$

Vrijeme izdvajanja teže kapljevine iz lakše:

$$
t_{\text {sep }, \mathrm{Lh}}=\frac{\mathrm{HLL}}{u_{\mathrm{Lh}}}=\frac{1,117 \mathrm{~m}}{0,00425 \mathrm{~m} \mathrm{~s}^{-1}}=262,9 \mathrm{~s}
$$

\section{Rekapitulacija}

\section{Plin:}

\begin{tabular}{l|c}
\hline $\begin{array}{l}\text { vrijeme zadržavanja } \\
\text { vrijeme izdvajanja kapljica kapljevine }\end{array}$ & $0,721 \mathrm{~s}$ \\
\hline \multicolumn{2}{c|}{ Lakša kapljevina: } \\
\hline \multicolumn{2}{c}{$0,369 \mathrm{~s}$} \\
\hline vrijeme zadržavanja & $383,2 \mathrm{~s}$ \\
vrijeme izdvajanja teže kapljevine & $262,9 \mathrm{~s}$ \\
\hline
\end{tabular}

Vremena zadržavanja su veća od potrebnih vremena odvajanja. Razlika nije jako velika i nema potrebe za korekcijom. U slučaju da je neko od vremena odvajanja veće, trebalo bi povećati duljinu separatora.

\section{Slivnik}

$\mathrm{Uz} L / D=2$ i $\mathrm{LLL}=0,15 \mathrm{~m}$ :

$$
\begin{gathered}
D_{S}=\sqrt{\frac{4 Q_{\mathrm{vLh}}}{\pi \cdot u_{\mathrm{LI}}}}=\sqrt{\frac{4 \cdot 0,000639 \mathrm{~m}^{3} \mathrm{~s}^{-1}}{\pi \cdot 0,00168 \mathrm{~ms}^{-1}}}=0,696 \mathrm{~m} \\
A_{\mathrm{S}}=\frac{D_{\mathrm{S}}{ }^{2} \cdot \pi}{4}=\frac{(0,696 \mathrm{~m})^{2} \cdot \pi}{4}=0,380 \mathrm{~m}^{2} \\
L_{S}=D_{\mathrm{S}} \cdot L / D=0,696 \mathrm{~m} \cdot 2=1,393 \mathrm{~m} \\
\mathrm{NLL}_{S}=\mathrm{LLL}_{\mathrm{S}}+\frac{V_{\mathrm{hLh}}}{A_{\mathrm{S}}}=0,15 \mathrm{~m}+\frac{0,193 \mathrm{~m}^{3}}{0,380 \mathrm{~m}^{2}}=0,653 \mathrm{~m} \\
\mathrm{HLL}_{S}=\mathrm{NLL}_{S}+\frac{V_{\mathrm{SLh}}}{A_{S}}=0,653 \mathrm{~m}+\frac{0,0767 \mathrm{~m}^{3}}{0,380 \mathrm{~m}^{2}}=0,855 \mathrm{~m}
\end{gathered}
$$

Vrijeme zadržavanja:

$$
t_{\mathrm{hLh}}=\frac{A_{\mathrm{S}} \cdot \mathrm{NLL}_{\mathrm{S}}}{Q_{\mathrm{vLh}}}=\frac{0,380 \mathrm{~m}^{2} \cdot 0,653 \mathrm{~m}}{0,000634 \mathrm{~m}^{3} \mathrm{~s}^{-1}}=389,4 \mathrm{~s}
$$

Vrijeme izdvajanja lakše kapljevine iz teže:

$$
t_{\text {sep }, \mathrm{Ll}}=\frac{\mathrm{HLL}_{\mathrm{S}}}{u_{\mathrm{LI}}}=\frac{0,855 \mathrm{~m}}{0,00168 \mathrm{~ms}^{-1}}=509,4 \mathrm{~s}
$$

Vrijeme potrebno za izdvajanje lakše kapljevine iz teže znatno je veće od vremena zadržavanja teže kapljevine u slivniku. Da skratimo vrijeme izdvajanja, povećamo promjer slivnika.

Povećanjem promjera slivnika na $D_{\mathrm{s}}=0,850 \mathrm{~m}$ dobijemo:

\begin{tabular}{c|c}
\hline promjer & $0,850 \mathrm{~m}$ \\
duljina & $1,393 \mathrm{~m}$ \\
HLL & $0,623 \mathrm{~m}$ \\
NLL & $0,488 \mathrm{~m}$ \\
LLL & $0,150 \mathrm{~m}$ \\
vrijeme zadržavanja & $433,2 \mathrm{~s}$ \\
vrijeme izdvajanja & $371,3 \mathrm{~s}$ \\
\hline
\end{tabular}

Vrijeme zadržavanja je veće od vremena razdvajanja kapljevina, što zadovoljava i time je dimenzioniranje dovršeno. Obično se dobivene dimenzije zaokruže.

\section{Dimenzije priključaka}

Proračun priključaka dao je sljedeće:

\begin{tabular}{l|c}
\hline Namjena & Nazivni promjer \\
\hline ulaz pojne smjese & $12 "$ Sch 40 \\
izlaz plina & $12^{\prime \prime}$ Sch 40 \\
izlaz lakše kapljevine & 3 "Sch 40 \\
izlaz teže kapljevine & 2 "Sch 40 \\
\hline
\end{tabular}

Za detalje postupka i proračuna vidi primjer 1. 
10. Pad tlaka

\begin{tabular}{c|c}
\hline ulaz smjese & $822 \mathrm{~Pa}$ \\
izlaz plina & $134 \mathrm{~Pa}$
\end{tabular}

Za detalje postupka i proračuna vidi primjer 1 .

\section{Rekapitulacija dimenzija}

\begin{tabular}{c|r}
\hline \multicolumn{1}{c}{ Separator } \\
\hline promjer & $1420 \mathrm{~mm}$ \\
duljina & $2835 \mathrm{~mm}$ \\
H/D & 2,0 \\
HLL & $1117 \mathrm{~mm}$ \\
NLL & $716 \mathrm{~mm}$ \\
LLL & $250 \mathrm{~mm}$ \\
\hline \multicolumn{1}{c}{ Slivnik } \\
\hline promjer & $850 \mathrm{~mm}$ \\
visina & $1000 \mathrm{~mm}$ \\
HLL & $623 \mathrm{~mm}$ \\
NLL & $488 \mathrm{~mm}$ \\
LLL & $150 \mathrm{~mm}$ \\
\hline \multicolumn{1}{c|}{ Priključci } \\
\hline ulaz smjese & $12^{\prime \prime}$ Sch 40 \\
izlaz plina & $12^{\prime \prime}$ Sch 40 \\
izlaz lakše kapljevine & 3 " Sch 40 \\
izlaz teže kapljevine & 2 Sch 40 \\
\hline
\end{tabular}

Napomena: Promjer i visina separatora i visina slivnika su zaokruženi.

\section{Primjer 7. Trofazni vodoravni separator s pregradom}

Ovaj tip separatora je izmijenjeni konvencionalni separator tako da se normalni nivo kapljevine ne održava regulacijom već ga održava pregrada. To ima posljedicu da su volumeni zadržavanja kapljevine i poremećaja dio volumena preljeva.

Proračun se temelji na brzini plina u parnom prostoru separatora koja osigurava izdvajanje kapljica kapljevine iz plina i na dovoljnom vremenu zadržavanja obje kapljevine u separatoru za postizanje željenog odvajanja dviju kapljevina. Kao i u prethodnim primjerima ne računa se s volumenima podnica. Ti su volumeni neka vrsta sigurnosne margine.

\section{Podatci za proračun}

Treba načiniti proračun trofaznog separatora za odvajanje plinsko/kapljevite smjese sljedećih karakteristika:

$$
\text { protok plina, } Q_{\mathrm{vG}}=3000 \mathrm{~m}^{3} \mathrm{~h}^{-1}
$$

gustoća plina, $\rho_{\mathrm{G}}=6,5 \mathrm{~kg} \mathrm{~m}^{-3}$

viskoznost plina, $\mu_{\mathrm{G}}=0,01 \mathrm{mPa} \mathrm{s}$

protok lakše kapljevine, $Q_{\mathrm{vLI}}=10,0 \mathrm{~m}^{3} \mathrm{~h}^{-1}$

gustoća kapljevine, $\rho_{\mathrm{LI}}=785 \mathrm{~kg} \mathrm{~m}^{-3}$

viskoznost lakše kapljevine, $\mu_{\mathrm{LI}}=0,24 \mathrm{mPa} \mathrm{s}$

protok teže kapljevine, $Q_{\mathrm{vLh}}=20,0 \mathrm{~m}^{3} \mathrm{~h}^{-1}$

gustoća kapljevine, $\rho_{\mathrm{Lh}}=995 \mathrm{~kg} \mathrm{~m}^{-3}$

viskoznost teže kapljevine, $\mu_{\mathrm{Lh}}=0,682 \mathrm{mPa} \mathrm{s}$

granični promjer kapljice koja se odvaja iz plina, $D_{\mathrm{p}}=100 \mu \mathrm{m}$

radni tlak separatora, $p=10$ bar

u separator se ne ugrađuje odvajač kapljica

distributor ulazne smjese je deflegmator

vrijeme zadržavanja, $t_{\mathrm{h}}=5 \mathrm{~min}$

vrijeme poremećaja, $t_{\mathrm{s}}=3 \mathrm{~min}$

sigurnosna margina/sigurnosni faktor, $F_{\mathrm{s}}=1,15$

\section{Souders-Brownov K-faktor i granična brzina plina}

U separator će biti ugrađen odvajač kapljica, pa Souders-Brownov $K$-faktor računamo korelacijama za odvajače (Koch-Otto York) za radni tlak $p=10,0$ bar:

$$
\begin{aligned}
K & =\left(0,109727-4,4216 \cdot 10^{-4} \mathrm{p} / \mathrm{bar}\right) \mathrm{ms}^{-1} \\
& =\left(0,109727-4,4216 \cdot 10^{-4} \cdot 10\right) \mathrm{ms}^{-1} \\
& =0,1053 \mathrm{~m} \mathrm{~s}^{-1}
\end{aligned}
$$

Kako se ne ugrađuje odvajač kapljica, izračunati K-faktor dijelimo s 2 .

$$
K=0,05265 \mathrm{~m} \mathrm{~s}^{-1}
$$

Granična brzina plina iz jedn. 15 (računamo s lakšom kapljevinom):

$u_{\mathrm{t}}=u_{\mathrm{d}}=K \sqrt{\frac{\rho_{\mathrm{LI}}-\rho_{\mathrm{G}}}{\rho_{\mathrm{G}}}}=0,05265 \mathrm{~m} \mathrm{~s}^{-1} \sqrt{\frac{785-6,5}{6,5}}=0,576 \mathrm{~m} \mathrm{~s}^{-1}$

\section{Brzine odvajanja kapljevina iz Stokesove korelacije}

$$
\begin{aligned}
u_{\mathrm{Lh}} & =\frac{g}{18} D_{\mathrm{p}}^{2} \frac{\rho_{\mathrm{Lh}}-\rho_{\mathrm{LI}}}{\mu_{\mathrm{LI}}}=\frac{9,806}{18} \cdot\left(100 \cdot 10^{-6}\right)^{2} \frac{995-785}{0,00024} \mathrm{~m} \mathrm{~s}^{-1} \\
& =0,00477 \mathrm{~m} \mathrm{~s}^{-1}
\end{aligned}
$$

Brzina je veća od $0,00245 \mathrm{~m} \mathrm{~s}^{-1}$ pa uzimamo $u_{\mathrm{Lh}}=0,00425 \mathrm{~ms}^{-1}$.

$$
\begin{aligned}
u_{\mathrm{LI}} & =\frac{g}{18} D_{\mathrm{p}}^{2} \frac{\rho_{\mathrm{Lh}}-\rho_{\mathrm{LL}}}{\mu_{\mathrm{Lh}}}=\frac{9,806}{18} \cdot\left(100 \cdot 10^{-6}\right)^{2} \frac{995-785}{0,000682} \mathrm{~m} \mathrm{~s}^{-1} \\
& =0,00168 \mathrm{~m} \mathrm{~s}^{-1}
\end{aligned}
$$




\section{Volumeni zadržavanja i poremećaja}

Zadržaj:

$$
\begin{aligned}
V_{\mathrm{h}} & =t_{\mathrm{h}} \cdot\left(Q_{\mathrm{vLI}}+Q_{\mathrm{vLh}}\right) \\
& =5 \cdot 60 \mathrm{~s} \cdot(0,00319+0,00639) \mathrm{m}^{3} \mathrm{~s}^{-1} \\
& =2,875 \mathrm{~m}^{3}
\end{aligned}
$$

Poremećaj:

$$
\begin{aligned}
V_{\mathrm{s}} & =t_{\mathrm{s}} \cdot\left(Q_{\mathrm{vLL}}+Q_{\mathrm{vLh}}\right) \\
& =3 \cdot 60 \mathrm{~s} \cdot(0,00319+0,00639) \mathrm{m}^{3} \mathrm{~s}^{-1} \\
& =1,725 \mathrm{~m}^{3}
\end{aligned}
$$

\section{Promjer separatora}

Uzimamo da je omjer visine parnog prostora i promjera separatora 0,8 .

Uz radni tlak od 10 bar preporučeni omjer $L / D$ je između 1,5 i 3 . Uzimamo $L / D=2,5$.

Promjer separatora:

$$
\begin{gathered}
D_{\mathrm{i}}=\left[\frac{16\left(V_{\mathrm{h}}+V_{\mathrm{s}}\right)}{\pi \frac{H_{\mathrm{w}}}{D} \frac{L}{D}}\right]^{1 / 3}=\left[\frac{16(2,875+1,725) \mathrm{m}^{3}}{\pi \cdot 0,8 \cdot 2,5}\right]^{1 / 3}=2,271 \mathrm{~m} \\
L=D_{\mathrm{i}} \cdot L / D=2,271 \mathrm{~m} \cdot 2,5=5,678 \mathrm{~m} \\
A_{\mathrm{t}}=\frac{\pi D_{\mathrm{i}}^{2}}{4}=\frac{\pi \cdot(2,271 \mathrm{~m})^{2}}{4}=4,051 \mathrm{~m}^{2} \\
H_{\mathrm{w}}=0,8 \cdot 2,271 \mathrm{~m}=1,817 \mathrm{~m} \\
H_{\mathrm{v}}=0,2 \cdot 2,271 \mathrm{~m}=0,454 \mathrm{~m}
\end{gathered}
$$

Visina parnog prostora odgovara. Nema odvajača kapljica, pa je minimalna visina $H_{\mathrm{v}}=0,3 \mathrm{~m}$.

Površina presjeka parnog prostora

$H_{\sqrt{ }} / D_{\mathrm{i}}=0,454$. Iz korelacija za odnose površina i visine kružnog odsječka (tablica 30) $A_{v}=0,577 \mathrm{~m}^{2}$.

\section{Komora za lakšu kapljevinu}

Komora treba imati volumen koji će pokriti traženi volumen zadržavanja i volumen poremećaja a to je volumen između minimalnog i maksimalnog nivoa.

Visina minimalnog nivoa $\mathrm{u}$ komori: $\quad \mathrm{LLL}=250 \mathrm{~mm}$ Visina maksimalnog nivoa u komori: $\mathrm{HLL}=1500 \mathrm{~mm}$ Uz omjer $L L L / D_{\mathrm{i}}=0,250 / 2,271=0,110$ i korelacija za visinu i površinu kružnog odsječka (tablica 30): $A_{\mathrm{LLL}}=0,242 \mathrm{~m}^{2}$.

Uz omjer HLL/ $D_{\mathrm{i}}=1,5 / 2,271=0,661: A_{\mathrm{HLL}}=2,839 \mathrm{~m}^{2}$

$$
L_{2}=\frac{V_{\mathrm{h}}+V_{\mathrm{s}}}{A_{\mathrm{HLL}}-A_{\mathrm{LLL}}}=\frac{2,875 \mathrm{~m}^{3}+1,725 \mathrm{~m}^{3}}{2,839 \mathrm{~m}^{2}-0,242 \mathrm{~m}^{2}}=1,771 \mathrm{~m}
$$

\section{Komora za separaciju}

Uzimamo da je međufazna razina na polovini visine pregrade:

$$
\mathrm{IL}=H_{\mathrm{w}} / 2=1,817 / 2=0,909 \mathrm{~m} .
$$

Vrijeme izdvajanja

teža faza iz lakše:

$$
t_{\text {sep }, \text { Lh }}=\frac{H_{\mathrm{LI}}}{u_{\mathrm{Lh}}}=\frac{0,909 \mathrm{~m}}{0,00425 \mathrm{~m} \mathrm{~s}^{-1}}=213,7 \mathrm{~s}
$$

lakša faza iz teže:

$$
t_{\text {sep }, \mathrm{LI}}=\frac{H_{\mathrm{Lh}}}{u_{11}}=\frac{0,909 \mathrm{~m}}{0,00168 \mathrm{~m} \mathrm{~s}^{-1}}=541,5 \mathrm{~s}
$$

Uz omjer IL $/ D_{\mathrm{i}}=0,909 / 2,271=0,400$ :

$$
\begin{aligned}
A_{\mathrm{Lh}} & =0,373 \cdot 3,924=1,464 \mathrm{~m}^{2} \\
A_{\mathrm{LI}} & =A_{\mathrm{t}}-A_{\mathrm{v}}-A_{\mathrm{Lh}} \\
& =4,051 \mathrm{~m}^{2}-0,577 \mathrm{~m}^{2}-1,464 \mathrm{~m}^{2} \\
& =2,01 \mathrm{~m}^{2}
\end{aligned}
$$

Potrebna duljina komore

za izdvajanje teže kapljevine iz lakše:

$$
L_{1 L I}=t_{\text {sep }, \text { Lh }} \cdot \frac{Q_{\mathrm{VLI}}}{A_{\mathrm{LI}}}=213,7 \mathrm{~s} \cdot \frac{0,00319 \mathrm{~m}^{3} \mathrm{~s}^{-1}}{2,01 \mathrm{~m}^{2}}=0,339 \mathrm{~m}
$$

za izdvajanje lakše kapljevine iz teže:

$$
L_{1 \mathrm{Lh}}=t_{\text {sep }, \mathrm{LL}} \cdot \frac{Q_{\mathrm{vLh}}}{A_{\mathrm{Lh}}}=541,5 \mathrm{~s} \cdot \frac{0,00639 \mathrm{~m}^{3} \mathrm{~s}^{-1}}{1,464 \mathrm{~m}^{2}}=2,364 \mathrm{~m}
$$

\section{Duljina parnog prostora}

Brzina plina:

$$
u_{\mathrm{G}}=\frac{Q_{\mathrm{vG}}}{A_{\mathrm{v}}}=\frac{0,958 \mathrm{~m}^{3} \mathrm{~s}^{-1}}{0,577 \mathrm{~m}^{2}}=1,661 \mathrm{~m} \mathrm{~s}^{-1}
$$

Vrijeme potrebno za izdvajanje kapljica:

$$
t_{\text {sep }}=\frac{H_{\mathrm{v}}}{u_{D}}=\frac{0,454 \mathrm{~m}}{0,523 \mathrm{~m} \mathrm{~s}^{-1}}=0,869 \mathrm{~s}
$$

Minimalna duljina parnog prostora:

$$
L_{1 \mathrm{G}}=t_{\text {sep }} \cdot u_{\mathrm{G}}=0,869 \mathrm{~s} \cdot 1,661 \mathrm{~m} \mathrm{~s}^{-1}=1,444 \mathrm{~m}
$$




\section{Rekapitulacija}

Uzimamo da je duljina parnog prostora duljina komore za separaciju. Najveća minimalna duljina za odvajanje je 2,286 m (lakša kapljevina iz teže), stoga imamo:

\begin{tabular}{l|l}
\hline promjer & $2,270 \mathrm{~m}$ \\
visina pregrade & $1,820 \mathrm{~m}$ \\
duljina separatora $(L / D)$ & $5,680 \mathrm{~m}$ \\
duljina komore za lakšu kapljevinu & $1,620 \mathrm{~m}$ \\
duljina komore za separaciju & $4,060 \mathrm{~m}$ \\
minimalna duljina komore za separaciju (lakša & $2,286 \mathrm{~m}$ \\
kapljevina iz teže) &
\end{tabular}

Napomena: dimenzije su zaokružene.

Očito je da je zahtijevano vrijeme zadržavanja kapljevina u separatoru kontrolirajući faktor za dimenzioniranje. Ako smanjimo duljinu komore za separaciju, neće biti zadovoljeno traženo vrijeme zadržavanja. Ako smanjimo omjer $L / D$, smanjit će se duljina separatora, ali će se povećati promjer. Pri tome će se zbog veće visine slojeva povećati potrebno vrijeme separacije pa time i potrebna duljina komore za separaciju. U svakom slučaju optimalno rješenje se nalazi promjenom omjera $L / D$ koji će dati najpovoljniju cijenu (masu) separatora.

\section{Dimenzije priključaka}

Proračun priključaka dao je sljedeće:

\begin{tabular}{l|c}
\hline Namjena & Nazivni promjer \\
\hline ulaz pojne smjese & 14 " Sch 40 \\
izlaz plina & 14 "Sch 40 \\
izlaz lakše kapljevine & 2 "Sch 40 \\
izlaz teže kapljevine & 3 "Sch 40 \\
\hline
\end{tabular}

Za detalje postupka i proračuna vidi primjer 1.

\section{Pad tlaka}

\begin{tabular}{c|c}
\hline Ulaz smjese & $969 \mathrm{~Pa}$ \\
Izlaz plina & $174 \mathrm{~Pa}$ \\
\hline
\end{tabular}

Za detalje postupka i proračuna vidi primjer 1 .

\section{Primjer 8. Trofazni vodoravni separator s pregradom i komorom za lakšu kapljevinu}

Taj tip separatora je inačica separatora s pregradom prilagođen odvajanju trofazne smjese s malom količinom lakše kapljevine. Kako bi zbog male količine lakše kapljevine visinu međufaznog nivoa bilo teško regulirati, ugrađuje se komora za lakšu kapljevinu. To unosi dodatne kriterije pri dimenzioniranju o kojima će biti govora u nastavku.
Proračun se temelji na brzini plina u parnom prostoru separatora koja osigurava izdvajanje kapljica kapljevine iz plina i dovoljnom vremenu zadržavanja lakše kapljevine u separatoru za postizanje željenog odvajanja teže iz lakše kapljevine. Slivnik se posebno dimenzionira kao okomiti separator.

\section{Podatci za proračun}

Treba načiniti proračun trofaznog separatora za odvajanje plinsko/kapljevite smjese sljedećih karakteristika:

protok plina, $Q_{\mathrm{mG}}=2500 \mathrm{~m}^{3} \mathrm{~h}^{-1}$

gustoća plina, $\rho_{\mathrm{G}}=3,5 \mathrm{~kg} \mathrm{~m}^{-3}$

viskoznost plina, $\mu_{\mathrm{G}}=0,01 \mathrm{mPa} \mathrm{s}$

protok lakše kapljevine, $Q_{\mathrm{vL}}=1,0 \mathrm{~m}^{3} \mathrm{~h}^{-1}$

gustoća lakše kapljevine, $\rho_{\mathrm{LI}}=875 \mathrm{~kg} \mathrm{~m}^{-3}$

viskoznost lakše kapljevine, $\mu_{\mathrm{LI}}=0,24 \mathrm{mPa} \mathrm{s}$

protok teže kapljevine, $Q_{\mathrm{vLh}}=20,0 \mathrm{~m}^{3} \mathrm{~h}^{-1}$

gustoća teže kapljevine, $\rho_{\mathrm{Lh}}=995 \mathrm{~kg} \mathrm{~m}^{-3}$

viskoznost teže kapljevine, $\mu_{\mathrm{Lh}}=0,682 \mathrm{mPa} \mathrm{s}$

granični promjer kapljice koja se odvaja iz plina, $D_{\mathrm{p}}=100 \mathrm{~mm}$

radni tlak separatora, $p=2$ bar

u separator se ugrađuje odvajač kapljica

distributor ulazne smjese je deflegmator

vrijeme zadržavanja, $t_{\mathrm{h}}=15 \mathrm{~min}$

vrijeme poremećaja, $t_{\mathrm{s}}=15 \mathrm{~min}$

sigurnosna margina/sigurnosni faktor, $F_{\mathrm{s}}=1,15$

\section{Souders-Brownov K-faktor i granična brzina plina}

U separator neće biti ugrađen odvajač kapljica. Souders-Brownov $K$-faktor računamo korelacijom GPSA za radni tlak $p=2,0$ bar:

$$
\begin{aligned}
K & =\left(0,109727-4,4216 \cdot 10^{-4} \mathrm{p} / \mathrm{bar}\right) \mathrm{ms}^{-1} \\
& =\left(0,109727-4,4216 \cdot 10^{-4} \cdot 2\right) \mathrm{ms}^{-1} \\
& =0,1088 \mathrm{~m} \mathrm{~s}^{-1}
\end{aligned}
$$

Kako se ne ugrađuje odvajač kapljica, izračunati $K$-faktor dijelimo s 2.

$$
K=0,0544 \mathrm{~ms}^{-1}
$$

Granična brzina plina iz jedn. 15 (računamo s lakšom kapljevinom):

$$
\begin{aligned}
u_{\mathrm{t}} & =u_{\mathrm{d}}=K \sqrt{\frac{\rho_{\mathrm{LI}}-\rho_{\mathrm{G}}}{\rho_{\mathrm{G}}}} \\
& =0,0544 \mathrm{~m} \mathrm{~s}^{-1} \sqrt{\frac{785-3,5}{3,5}}=0,813 \mathrm{~m} \mathrm{~s}^{-1}
\end{aligned}
$$




\section{Brzine odvajanja kapljevina (Stokesova korelacija)}

$$
\begin{aligned}
u_{\mathrm{Lh}} & =\frac{g}{18} D_{\mathrm{p}}^{2} \frac{\rho_{\mathrm{Lh}}-\rho_{\mathrm{LI}}}{\mu_{\mathrm{Ll}}}=\frac{9,806}{18} \cdot\left(100 \cdot 10^{-6}\right)^{2} \frac{995-785}{0,00024} \mathrm{~m} \mathrm{~s}^{-1} \\
& =0,00477 \mathrm{~m} \mathrm{~s}^{-1}
\end{aligned}
$$

Brzina je veća od preporučene maksimalne i uzimamo $u_{\mathrm{Lh}}=0,00425 \mathrm{~m} \mathrm{~s}^{-1}$

$$
\begin{aligned}
u_{\mathrm{LI}} & =\frac{g}{18} D_{\mathrm{p}}^{2} \frac{\rho_{\mathrm{Lh}}-\rho_{\mathrm{LL}}}{\mu_{\mathrm{Lh}}}=\frac{9,806}{18} \cdot\left(100 \cdot 10^{-6}\right)^{2} \frac{995-785}{0,000682} \mathrm{~m} \mathrm{~s}^{-1} \\
& =0,00168 \mathrm{~m} \mathrm{~s}^{-1}
\end{aligned}
$$

\section{Vrijeme zadržavanja lakše i teže kapljevine}

Za sabirnu posudu kiselih voda u rafinerijama preporučuje se vrijeme zadržavanja od 60 min. U kemijskoj procesnoj industriji obično se uzima 10-15 min. Za sabirne posude regeneratora otopine amina vrijeme zadržavanja je obično $10-15 \mathrm{~min}$.

Uzimamo: $t_{\mathrm{hLl}}=15 \mathrm{~min} ; t_{\mathrm{hLh}}=15 \mathrm{~min}$.

\section{Promjer i površina presjeka separatora}

Uz radni tlak $p=2$ bar uzimamo omjer $L / D=2,0$.

Promjer separatora:

$$
\begin{aligned}
D_{\mathrm{i}} & =\left[\frac{4\left(Q_{\mathrm{vLl}} \cdot \mathrm{t}_{\mathrm{hLI}}+Q_{\mathrm{vLh}} \cdot \mathrm{t}_{\mathrm{hLh}}\right)}{0,7 \cdot \pi \cdot \frac{L}{D}}\right]^{1 / 3} \\
& =\left[\frac{4\left(0,000319 \mathrm{~m}^{3} \mathrm{~s}^{-1} \cdot 15 \cdot 60 \mathrm{~s}+0,00639 \mathrm{~m}^{3} \mathrm{~s}^{-1} \cdot 15 \cdot 60 \mathrm{~s}\right)}{0,7 \cdot \pi \cdot 2}\right]^{1 / 3} \\
& =1,764 \mathrm{~m}
\end{aligned}
$$

Površina presjeka:

$$
A_{t}=\frac{\pi D_{i}^{2}}{4}=\frac{\pi \cdot(1,764 \mathrm{~m})^{2}}{4}=2,444 \mathrm{~m}^{2}
$$

\section{Visina i površina presjeka parnog prostora

$$
H_{\mathrm{v}}=0,2 \cdot D_{\mathrm{i}}=0,2 \cdot 1,764 \mathrm{~m}=0,353 \mathrm{~m}
$$

Separator je bez odvajača kapljica i minimalna preporučena visina je $H_{\mathrm{v}, \min }=0,3 \mathrm{~m}$.

$H_{\mathrm{v}}=0,353$ m zadovoljava.

$$
x=H_{\mathrm{v}} / D_{\mathrm{i}}=0,2
$$

Iz korelacije za odnose visine i površine kružnog odsječka (tablica 30) $A_{\mathrm{v}}=0,348 \mathrm{~m}^{2}$.
6. Duljina sekcije za separaciju, $L_{1}$

$$
\begin{aligned}
L_{1} & =\frac{Q_{v L I} \cdot t_{h L I}+Q_{v L h} \cdot t_{h L h}}{A_{t}-A_{v}} \\
& =\frac{0,000319 \mathrm{~m}^{3} \mathrm{~s}^{-1} \cdot 15 \cdot 60 \mathrm{~s}+0,00639 \mathrm{~m}^{3} \mathrm{~s}^{-1} \cdot 15 \cdot 60 \mathrm{~s}}{2,444 \mathrm{~m}^{2}-0,348 \mathrm{~m}^{2}} \\
& =2,880 \mathrm{~m}
\end{aligned}
$$

\section{Minimalna potrebna duljina sekcije za separaciju}

Visina pregrade komore lakše kapljevine:

$$
H_{\mathrm{w} 1}=D_{\mathrm{i}}-H_{\mathrm{v}}=1,764 \mathrm{~m}-0,353 \mathrm{~m}=1,411 \mathrm{~m} .
$$

Uzimamo da je visina slobodnog prostora ispod komore $0,25 \mathrm{~m}$.

Visina komore:

$$
H_{\text {Lkomora }}=1,411 \mathrm{~m}-0,250 \mathrm{~m}=1,161 \mathrm{~m} .
$$

Uzmemo da je visina sloja lakše kapljevine $H_{\text {sLl }}=0,5 \mathrm{~m}$.

Kontroliramo daje li ta visina sloja prihvatljivu razliku visina pregrada lakše i teže kapljevine.

$$
\Delta H_{\mathrm{w}}=H_{\mathrm{SLI}} \cdot\left(1-\frac{\rho_{\mathrm{LI}}}{\rho_{\mathrm{LL}}}\right)=0,5 \mathrm{~m} \cdot\left(1-\frac{785}{995}\right)=0,106 \mathrm{~m}
$$

Razlika od 106 mm zadovoljava.

Visina sloja lakše kapljevine: $H_{\mathrm{SLI}}=0,5 \mathrm{~m}$;

visina sloja teže kapljevine:

$$
\begin{aligned}
H_{\text {SLh }} & =D_{\mathrm{i}}-H_{\mathrm{v}}-H_{\text {sLl }} \\
& =1,764 \mathrm{~m}-0,353 \mathrm{~m}-0,5 \mathrm{~m} \\
& =0,911 \mathrm{~m} .
\end{aligned}
$$

Uz $H_{\text {SLL }} / D_{\mathrm{i}}=0,5165$ površina presjeka sloja teže kapljevine: $A_{\mathrm{Lh}}=1,273 \mathrm{~m}^{2}$.

Površina sloja presjeka lakše kapljevine:

$$
\begin{aligned}
A_{\mathrm{LI}} & =A_{\mathrm{t}}-A_{\mathrm{v}}-A_{\mathrm{Lh}} \\
& =2,444 \mathrm{~m}-0,348 \mathrm{~m}-1,273 \mathrm{~m} \\
& =0,823 \mathrm{~m}^{2}
\end{aligned}
$$

Minimalna duljina sekcije za izdvajanje kapljica kapljevine iz plina:

$$
\begin{gathered}
u_{\mathrm{G}}=\frac{Q_{\mathrm{vG}}}{A_{\mathrm{v}}}=\frac{0,799 \mathrm{~m}^{3} \mathrm{~s}^{-1}}{0,348 \mathrm{~m}^{2}}=2,296 \mathrm{~m} \mathrm{~s}^{-1} \\
t_{\text {sep }}=\frac{H_{\mathrm{v}}}{u_{\mathrm{d}}}=\frac{0,353 \mathrm{~m}}{0,813 \mathrm{~m} \mathrm{~s}^{-1}}=0,434 \mathrm{~s} \\
L_{\text {min }, \mathrm{G}}=t_{\text {sep }} \cdot u_{\mathrm{G}}=0,434 \mathrm{~s} \cdot 2,296 \mathrm{~m} \mathrm{~s}^{-1}=0,996 \mathrm{~m}
\end{gathered}
$$


Minimalna duljina sekcije za izdvajanje teže kapljevine iz lakše:

$$
\begin{gathered}
u_{\mathrm{LI}}=\frac{Q_{\mathrm{vLI}}}{A_{\mathrm{LI}}}=\frac{0,000319 \mathrm{~m}^{3} \mathrm{~s}^{-1}}{0,823 \mathrm{~m}^{2}}=0,000388 \mathrm{~m} \mathrm{~s}^{-1} \\
t_{\text {sep }, \mathrm{Lh}}=\frac{H_{\mathrm{SLh}}}{u_{\mathrm{Lh}}}=\frac{0,5 \mathrm{~m}}{0,00425 \mathrm{~m} \mathrm{~s}^{-1}}=117,6 \mathrm{~s} \\
L_{\min , \mathrm{LL}}=t_{\text {sep }, \mathrm{Ll}} \cdot u_{\mathrm{LL}}=117,6 \mathrm{~s} \cdot 0,000388 \mathrm{~m} \mathrm{~s}^{-1}=0,0456 \mathrm{~m}
\end{gathered}
$$

Minimalna duljina sekcije za izdvajanje lakše kapljevine iz teže:

$$
\begin{gathered}
u_{\mathrm{Lh}}=\frac{Q_{\mathrm{vLh}}}{A_{\mathrm{Lh}}}=\frac{0,00639 \mathrm{~m}^{3} \mathrm{~s}^{-1}}{1,273 \mathrm{~m}^{2}}=0,00502 \mathrm{~m} \mathrm{~s}^{-1} \\
t_{\mathrm{sep}, \mathrm{Lh}}=\frac{H_{\mathrm{SLI}}}{u_{\mathrm{Ll}}}=\frac{0,911 \mathrm{~m}}{0,00502 \mathrm{~m} \mathrm{~s}^{-1}}=181,5 \mathrm{~s} \\
L_{\text {min, Lh }}=t_{\mathrm{sep}, \mathrm{Lh}} \cdot u_{\mathrm{Lh}}=181,5 \mathrm{~s} \cdot 0,00502 \mathrm{~m} \mathrm{~s}^{-1}=0,911 \mathrm{~m}
\end{gathered}
$$

\section{Rekapitulacija}

Duljina sekcije $L_{1}$ $2,880 \mathrm{~m}$

Minimalna duljina za izdvajanje kapljica iz plina

$0,996 \mathrm{~m}$

Minimalna duljina za izdvajanje teže kapljevine iz lakše

$0,046 \mathrm{~m}$

Minimalna duljina za izdvajanje lakše kapljevine iz teže

$0,991 \mathrm{~m}$
Površina presjeka komore pod između LLL i HLL:

$$
\begin{aligned}
& x=\mathrm{HLL} / D_{\mathrm{i}}=0,665 ; y=0,706 ; A_{\mathrm{HLL}}=1,726 \mathrm{~m}^{2} \\
& x=\mathrm{LLL} / D_{\mathrm{i}}=0,210 ; y=0,152 ; A_{\mathrm{LLL}}=0,373 \mathrm{~m}^{2}
\end{aligned}
$$

Širina komore:

$$
\begin{aligned}
L_{2} & =\frac{\left(t_{\mathrm{h}}+t_{\mathrm{s}}\right) \cdot Q_{\mathrm{VLL}}}{\left(A_{\mathrm{HLL}}-A_{\mathrm{LLL}}\right)} \\
& =\frac{(10+5) \cdot 60 \mathrm{~s} \cdot 0,000319 \mathrm{~m}^{3} \mathrm{~s}^{-1}}{\left(1,726 \mathrm{~m}^{2}-0,373 \mathrm{~m}^{2}\right)} \\
& =0,212 \mathrm{~m}
\end{aligned}
$$

Uzimamo da je $L_{2}=0,3 \mathrm{~m}$

Duljina $L_{3}$

Uzimamo da je razmak između komore za lakšu kapljevinu i pregrade preljeva $L_{3}=0,3 \mathrm{~m}$.

\section{Preljev za težu kapljevinu}

Visina pregrade:

$$
H_{\mathrm{wp}}=H_{\mathrm{wk}}-\Delta H_{\mathrm{w}}=1,191-0,106=1,085 \mathrm{~m}
$$

Visine HLL i LLL u preljevu:

$$
\mathrm{HLL}=H_{\mathrm{wp}}-0,15=1,008-0,150=0,938 \mathrm{~m}
$$

$$
\mathrm{LLL}=0,150 \mathrm{~m}
$$

Površina presjeka preljeva pod između LLL i HLL:

$$
\begin{aligned}
& x=\mathrm{HLL} / D_{\mathrm{i}}=0,531 ; A_{\mathrm{HLL}}=1,321 \mathrm{~m}^{2} \\
& x=\mathrm{LLL} / D_{\mathrm{i}}=0,0848 ; A_{\mathrm{LLL}}=0,100 \mathrm{~m}^{2}
\end{aligned}
$$

Širina komore:

$$
\begin{aligned}
L_{4} & =\frac{\left(t_{\mathrm{h}}+t_{\mathrm{s}}\right) \cdot Q_{\mathrm{vLh}}}{A_{\mathrm{HLL}}-A_{\mathrm{LLL}}} \\
& =\frac{(10+5) \cdot 60 \mathrm{~s} \cdot 0,00639 \mathrm{~m}^{3} \mathrm{~s}^{-1}}{1,316 \mathrm{~m}^{2}-0,100 \mathrm{~m}^{2}} \\
& =4,728 \mathrm{~m}
\end{aligned}
$$

11. Duljina separatora

$$
\begin{aligned}
L & =L_{1}+L_{2}+L_{3}+L_{4} \\
& =2,885 \mathrm{~m}+0,3 \mathrm{~m}+0,3 \mathrm{~m}+4,728 \mathrm{~m} \\
& =8,208 \mathrm{~m}
\end{aligned}
$$

$\mathrm{LLL}=H_{\mathrm{kb}}+0,15 \mathrm{~m}=0,221 \mathrm{~m}+0,15 \mathrm{~m}=0,371 \mathrm{~m}$ 


\section{Rekapitulacija}

\section{Promjer}

$1,764 \mathrm{~m}$

$8,208 \mathrm{~m}$

Duljina sekcije separacije

Visina pregrade komore za lakšu kapljevinu

Visina komore za lakšu kapljevinu

Širina komore za lakšu kapljevinu

Razmak između komore za lakšu kapljevinu i pregrade preljeva

Visina pregrade preljeva

Širina preljeva

L/D

$2,885 \mathrm{~m}$

$1,414 \mathrm{~m}$

$1,193 \mathrm{~m}$

$0,3 \mathrm{~m}$

$0,3 \mathrm{~m}$

$1,088 \mathrm{~m}$

$4,821 \mathrm{~m}$

4,653

To je relativno velik $L / D$. Pokušaj s promjerom $D_{\mathrm{i}}=2,25 \mathrm{~m}$ dao je:

\begin{tabular}{l|r}
\hline Promjer & $2,250 \mathrm{~m}$ \\
Duljina & $5,003 \mathrm{~m}$ \\
Duljina sekcije separacije & $1,771 \mathrm{~m}$ \\
Visina pregrade komore za lakšu kapljevinu & $1,800 \mathrm{~m}$ \\
Visina komore za lakšu kapljevinu & $1,519 \mathrm{~m}$ \\
Širina komore za lakšu kapljevinu & $0,3 \mathrm{~m}$ \\
Razmak između komore za lakšu kapljevinu i & $0,3 \mathrm{~m}$ \\
pregrade preljeva & \\
\hline
\end{tabular}

\begin{tabular}{l|r}
\hline Visina pregrade preljeva & $1,413 \mathrm{~m}$ \\
Širina preljeva & $2,632 \mathrm{~m}$ \\
L/D & 2,224 \\
\hline
\end{tabular}

To je prihvatljiv rezultat.

\section{Dimenzije priključaka}

Postupak proračuna prikazan je prethodnim primjerima, pa se neće detaljno prikazivati.

\begin{tabular}{l|c}
\hline \multicolumn{1}{c|}{ Namjena } & Nazivni promjer \\
\hline ulaz pojne smjese & $12^{\prime \prime}$ Sch 10 \\
izlaz plina & $12^{\prime \prime}$ Sch 10 \\
izlaz lakše kapljevine & 1 "Sch 10 \\
izlaz teže kapljevine & 3 " Sch 10 \\
\hline
\end{tabular}

Za detalje postupka i proračuna vidi primjer 1.

14. Pad tlaka

\begin{tabular}{l|c}
\hline Ulaz smjese & $714 \mathrm{~Pa}$ \\
Izlaz plina & $93 \mathrm{~Pa}$ \\
\hline
\end{tabular}

Za detalje postupka i proračuna vidi primjer 1. 


\section{Popis kratica i simbola}

\section{List of abbreviations and symbols}

$\mathrm{A}_{\text {HLL }} \quad$ - površina presjeka koji zauzima kapljevina do visokog nivoa, $\mathrm{m}^{2}$

- liquid cross-section area at high level, $\mathrm{m}^{2}$

$A_{\mathrm{LLL}} \quad$ - površina presjeka koji zauzima kapljevina do niskog nivoa, $\mathrm{m}^{2}$

- liquid cross-section area at low level, $\mathrm{m}^{2}$

$A_{\mathrm{Lh}} \quad$ - površina presjeka volumena zadržaja teže kapljevine, $\mathrm{m}^{2}$

- hold up volume cross-section area of heavy liquid, $\mathrm{m}^{2}$

$A_{\mathrm{LI}} \quad$ - površina presjeka volumena zadržaja lakše kapljevine, $\mathrm{m}^{2}$

- hold up volume cross-section area of light liquid, $\mathrm{m}^{2}$

$A_{\mathrm{s}} \quad$ - površina presjeka slivnika, $\mathrm{m}^{2}$

- cross-section area of boot, $\mathrm{m}^{2}$

$A_{\mathrm{s}} \quad$ - površina presjeka volumena poremećaja kod vodoravnog separatora, $\mathrm{m}^{2}$

- surge volume cross-section area in horizontal separator, $\mathrm{m}^{2}$

$A_{t} \quad$ - površina presjeka separatora, $\mathrm{m}^{2}$

- separator cross-section area, $\mathrm{m}^{2}$

$A_{v} \quad$ - površina presjeka parnog prostora kod vodoravnog separatora, $\mathrm{m}^{2}$

- vapour space cross-section area in horizontal separator, $\mathrm{m}^{2}$

D - promjer, $\mathrm{m}$

- diameter, $m$

$D_{\mathrm{i}} \quad$ - unutarnji promjer separatora, $\mathrm{m}, \mathrm{mm}$

- separator inner diameter, $\mathrm{m}, \mathrm{mm}$

$D_{\mathrm{p}} \quad$ - promjer kapi, $\mathrm{mm}$

- drop diameter, $\mathrm{mm}$

$D_{\mathrm{S}} \quad$ - unutarnji promjer slivnika, $\mathrm{m}$

- boot inner diameter, $\mathrm{m}$

$F_{\mathrm{s}} \quad$ - sigurnosni faktor

- safety factor

g - gravitacijsko ubrzanje, $g=9,806 \mathrm{~m} \mathrm{~s}^{-2}$

- gravitational acceleration

H - visina, $\mathrm{m}$

- height, $m$

$H_{\mathrm{h}} \quad$ - visina volumena zadržavanja, $\mathrm{m}$

- hold up volume height, $\mathrm{m}$

$H_{\mathrm{k}} \quad$ - visina komore, $\mathrm{m}$

- bucket height, $\mathrm{m}$

$H_{\mathrm{kb}}$ - visina dna komore, $\mathrm{m}$

- bucket bottom height, $\mathrm{m}$

$H_{\mathrm{kt}} \quad$ - visina vrha komore, $\mathrm{m}$

- bucket height, $\mathrm{m}$

$H_{1} \quad$ - visina od međufaznog nivoa do osi priključka za odvod lakše kapljevine, $\mathrm{m}$

- height from interface level to light liquid outlet nozzle centre line, $\mathrm{m}$

$H_{\text {Lh }} \quad$ - visina sloja teže kapljevine, m

- height of heavy liquid layer, $m$

$H_{\sqcup} \quad$ - visina sloja lakše kapljevine, $\mathrm{m}$

- height of light liquid layer, m
$H_{\mathrm{s}} \quad$ - visina volumena poremećaja, m

- surge volume height, $m$

$H_{v} \quad$ - visina parnog prostora (vodoravni separator), m

- vapour space height (horizontal separator), m

$H_{\mathrm{w}} \quad$ - visina pregrade, $\mathrm{m}$

- weir height, $m$

HLL - visoki nivo kapljevine, $m$

- high liquid level, m

$\mathrm{HLL}_{\mathrm{s}}$ - visoki nivo kapljevine u slivniku, m

- high liquid level, m

$K$ - Souders-Brownov faktor, $K$-faktor, $\mathrm{m} \mathrm{s}^{-1}$

- Souders-Brown factor, K-factor, $\mathrm{m} \mathrm{s}^{-1}$

IL $\quad-$ međufazni nivo

- interface level

L $\quad$ - duljina, $m$

- length, $\mathrm{m}$

$L_{\min } \quad$ - minimalna duljina vodoravnog separatora, $\mathrm{m}$

- minimum horizontal separator length, $m$

$L_{\mathrm{s}} \quad$ - duljina slivnika, $\mathrm{m}$

- boot length, $\mathrm{m}$

LLL - niski nivo kapljevine, $\mathrm{m}$

- low liquid level, m

NLL - normalni nivo kapljevine, $\mathrm{m}$

- normal liquid level, $\mathrm{m}$

$\mathrm{NLL}_{s} \quad$ - normalni nivo kapljevine u slivniku, $\mathrm{m}$

- normal liquid level, m

p - tlak, bar

- pressure, bar

$Q_{\mathrm{mLh}} \quad$ - maseni protok teže kapljevine, $\mathrm{kgh}^{-1}$

- heavy liquid mass flux, $\mathrm{kgh}^{-1}$

$Q_{\mathrm{mLl}} \quad$ - maseni protok lakše kapljevine, $\mathrm{kg} \mathrm{h}^{-1}$

- light liquid mass flow, $\mathrm{kgh}^{-1}$

$Q_{v G} \quad$ - volumni protok plina, $\mathrm{m}^{3} \mathrm{~h}^{-1}, \mathrm{~m}^{3} \mathrm{~s}^{-1}$

- gas volume flux, $\mathrm{m}^{3} \mathrm{~h}^{-1}, \mathrm{~m}^{3} \mathrm{~s}^{-1}$

$Q_{\text {vLh }} \quad$ - volumni protok teže kapljevine, $\mathrm{m}^{3} \mathrm{~h}^{-1}, \mathrm{~m}^{3} \mathrm{~s}^{-1}$

- heavy liquid volume flux, $\mathrm{m}^{3} \mathrm{~h}^{-1}, \mathrm{~m}^{3} \mathrm{~s}^{-1}$

$Q_{\mathrm{vLI}} \quad$ - volumni protok lakše kapljevine, $\mathrm{m}^{3} \mathrm{~h}^{-1}, \mathrm{~m}^{3} \mathrm{~s}^{-1}$

- light liquid volume flux, $\mathrm{m}^{3} \mathrm{~h}^{-1}, \mathrm{~m}^{3} \mathrm{~s}^{-1}$

$t_{\mathrm{h}} \quad$ - vrijeme zadržavanja kapljevine u separatoru, min, $\mathrm{s}$

- hold up time, min, s

$t_{\text {hLh }}$ - vrijeme zadržavanja teže kapljevine u separatoru, s

- heavy liquid holdup time, s

$t_{\mathrm{hLI}} \quad$ - vrijeme zadržavanja lakše kapljevine u separatoru, s

- light liquid holdup time, s

$t_{\mathrm{s}} \quad-$ vrijeme poremećaja protoka, $\mathrm{min}, \mathrm{s}$

- feed surge time, min, s

$t_{\text {sep }} \quad$ - vrijeme odvajanja kapljevite faze, s

- liquid phase separation time, s

$t_{\text {sep,Lh }} \quad$ - vrijeme potrebno za izdvajanje kapljica teže kapljevine iz lakše, s

- heavy liquid dropout time, s

$t_{\text {sep,LI }} \quad$ - vrijeme potrebno za izdvajanje kapljica

lakše kapljevine iz teže, s

- light liquid dropout time, s

$u_{\mathrm{d}} \quad$ - projektna brzina plina kroz odvajač kapljica, $\mathrm{m} \mathrm{s}^{-1}$

- gas velocity through mist eliminator, $\mathrm{m} \mathrm{s}^{-1}$ 


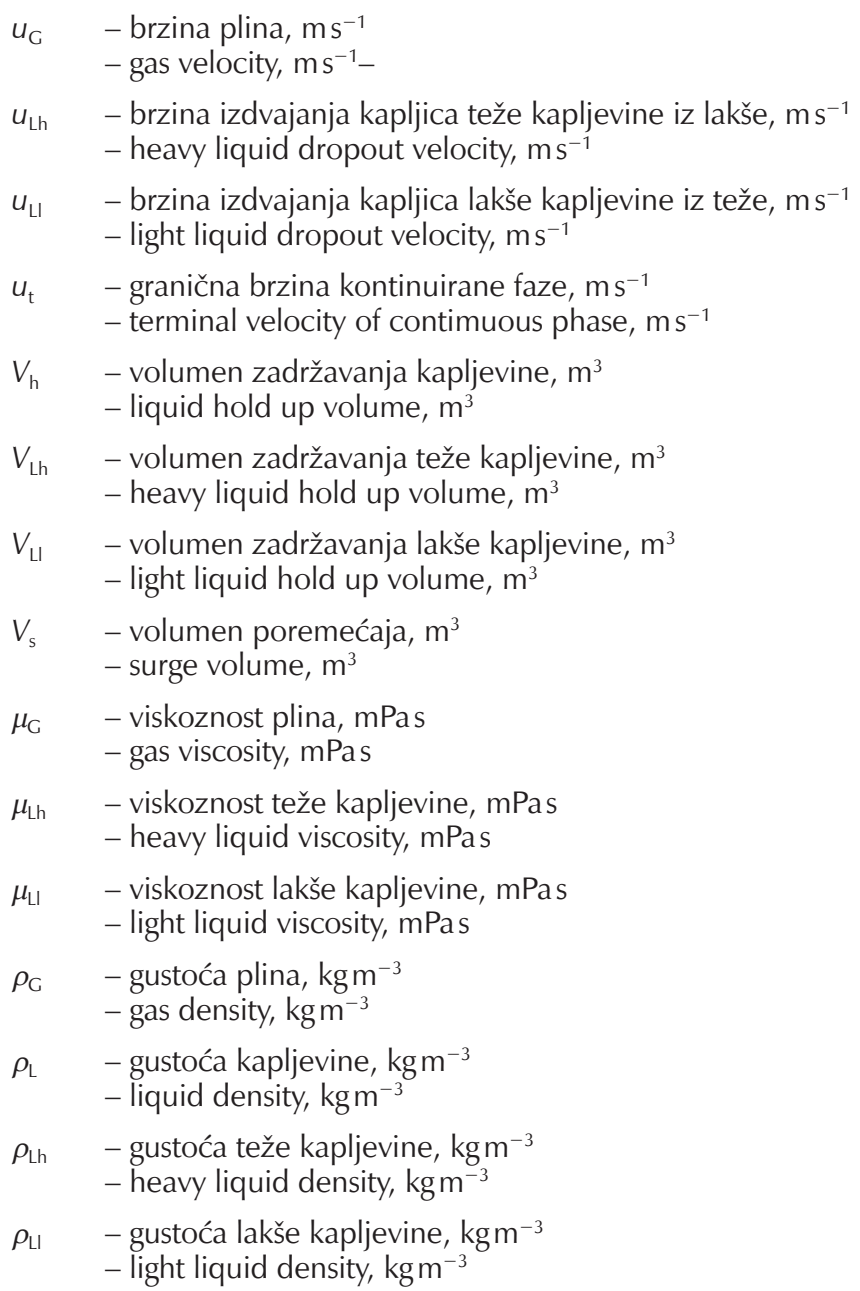

\section{Literatura \\ References}

1. D. W. Green, R. H. Perry (ur.), Perry's Chemical Engineers' Handbook 8. izd., McGraw-Hill, New York, 2008.

2. API Standard 521 Pressure-Relieving and Depressuring Systems.

3. W. L. McCabe, J. C. Smith, Unit Operations of Chemical Engineering, 3. izd., McGraw-Hill, New York, 1976.

4. F. H. Wu, Drum separator design. A new approach, Chem. Eng. 91 (7) (1984) 74.

5. A. H. Selker, C. A. Sleicher, Factors affecting which phase will disperse when immiscible liquids are stirred together, Can. J. Chem. Eng. 43 (1965) 298, doi: http://dx.doi.org/10.1002/ cjce. 5450430606 .

6. Gas/liquid separators - Type selection and design rules,
Shell GSI, 2007.

7. S. Rahimi, Three phase separators - Inlet devices, URL: http://chemwork.org/PDF/board/Three\%20phase\%20Separator\%20-\%20lnlet\%20Devices.pdf.

8. S. A. Ziebold, Demystifying mist eliminator selection, Chem. Eng. 107 (5) (2000) 94.

9. M. Bothamley, Gas/Liquids Separators - Part 2, Quantifying Separation Performance, Oil and Gas Facilities 2 (5) (2013) 35.

10. C. L. Carpenter, D. F. Othmer, Entrainment removal by a wire-mesh separator, AIChE J. 1 (4) (1955) 549, doi: http:// dx.doi.org/10.1002/aic.690010428.

11. J. P. Monat, K. J. McNulty, I. S. Michelson, O. V. Hansen, Accurate evaluation of chevron mist eliminators, Chem. Eng. Progr. 82 (1986) 32.

12. API specification 12J. Specification for Oil and Gas Separators.

13. GPSA Engineering Data Book, 10. izd. 1987, Vol. 1, Chapter 7: Separators. Gas Processors and Suppliers Association, Tulsa.

14. Process design of gas(vapour)-liquid separators (Project standard and specifications), Rev. 01, KLM Technology Group, Johor Bahru, 2011.

15. F. Boukadi, V. Singh, R. Trabelsi, F. Sebring, D. Allen, V. Pai, Appropriate separator sizing: A modified Stewart and Arnold method, Model. Simulat. Eng. 2012 (2012) Article ID 721814, doi: http://dx.doi.org/10.1155/2012/721814.

16. NORSOK Standard P-100, Process systems, Rev 2, Norwegian Technology Centre, Oslo, 2001.

17. P. Fabian, R. Cusack, P. Hennessey, N. Neuman, Demystifying the selection of mist eliminators. Part 1, Chem. Eng. 100 (11) (1993) 148-156.

18. W. D. Monnery,W. Y. Svrcek, Successfully specify threephase separators, Chem. Eng. Prog. 90 (9) (1994) 29-40.

19. W. Y. Svrcek, W. D. Monnery, Design two-phase separators within the right limits, Chem. Eng. Prog. 80 (1993) 53.

20. S. Rahimi, Three phase separators - Gas internals, URL: http://www.chemwork.org/PDF/board/Three\%20phase\%20 Separator\%20-\%20Gas\%20Internals.pdf.

21. S. Rahimi, Three phase separators - Times definition, URL: http://www.chemwork.org/PDF/board/Three\%20Phase\%20 Separators\%20-\%20Times\%20Definition.pdf.

22. R. N. Watkins, Sizing separators and accumulators, Hydrocarbon Process. 46 (11) (1967) 253-256.

23. A. Gerunda, How to Size Liquid-Vapor Separators, Chem. Eng. 88 (9) (1981) 81-84.

24. H. Sarma, How to Size Gas Scrubber, Hydrocarbon Process. 69 (1981) 251-255

25. P. G. Talavera, Selecting Gas/Liquid Separators, Hydrocarbon Process. 69 (6) (1990) 81-84. 


\title{
SUMMARY
}

\section{Gravity Vapour/Liquid Separators. Part IV.}

\author{
Eduard Beer
}

Procedures and calculation examples for horizontal three-phase gravity separators.

\section{Keywords}

Gravity separator, gas/liquid/liquid separator, design procedures

Aleja Blaža Jurišića 9

10000 Zagreb

Professional paper

Received January 5, 2015

Accepted December 7, 2015 